\title{
Economic Fluctuations and Insurance Industry Crisis: the History, Status Quo and the Future
}

\author{
Zhenhua Guo \\ School of Finance, Shanghai University of International Business and Economics, Shanghai 201620, China
}

Received 11 December 2015

Accepted 15 February 2016

\begin{abstract}
The healthy development of insurance industry influenced the stability of country's financial system. In recent years, the insurance industry has developed rapidly in China, but also hid the huge risks in it. As the economic growth rate slow down, China's insurance industry may also encounter with crisis that Japanese and Taiwan has faced. In this paper, by analyzing the reasons and mechanisms of insurance industry crisis in Japan and Taiwan, found the insurance industry crisis closely related to the economic fluctuation, and provided some warnings and references to the insurance industry of China.
\end{abstract}

Keywords: Economic fluctuations, insurance industry crisis, interest margin loss

\section{经济波动与保险业危机：历史、现状与未来}

\section{郭振华}

上海对外经贸大学金融学院, 上海, 201620

摘要：保险业的健康发展关乎国家金融体系稳定, 近些年来, 我国保险业发展迅速, 取得了骄人的成绩, 但在成绩的背后也隐藏了巨大的风险, 随着经济增长减速, 我国保险业也可能遭遇日本, 台湾曾经遭遇过的保险 业危机。本文通过梳理日本、台湾经济过的保险业危机, 探讨其深层次原因与机制, 发现其与经济波动的密切联 系，为我国保险业提供一些警示与借鉴。

关键字: 经济波动、保险业危机、利差损

\section{1. 中国保险业发展概况及保险业特征}

\section{1 中国保险业发展简述}

自 1980 年国内保险公司复业以来, 我国保险业 发展迅速, 从一个基础薄弱的行业逐步成长为一个 关系国计民生的重要行业。2014 年财险保费收入达 到 7544.4 亿, 相比 2002 年, 增长了近 10 倍; 寿险 保费收入达到 12690.28 亿, 是 2002 年寿险保费收入 的 5.58 倍。截至 2014 年底, 财险业资产规模达到 14061.48 亿元, 相比 2002 年增长了 14.9 倍; 寿险业 资产规模达到 82487.2 亿元, 相比 2002 年增长了 16 倍。我国财产保险业和寿险业保费和资产增长态势 见图 1 和图 2。

\section{2 我国保险业特征}

保险业有一些特有的特征，这些特征也决定了 保险业的风险特点:

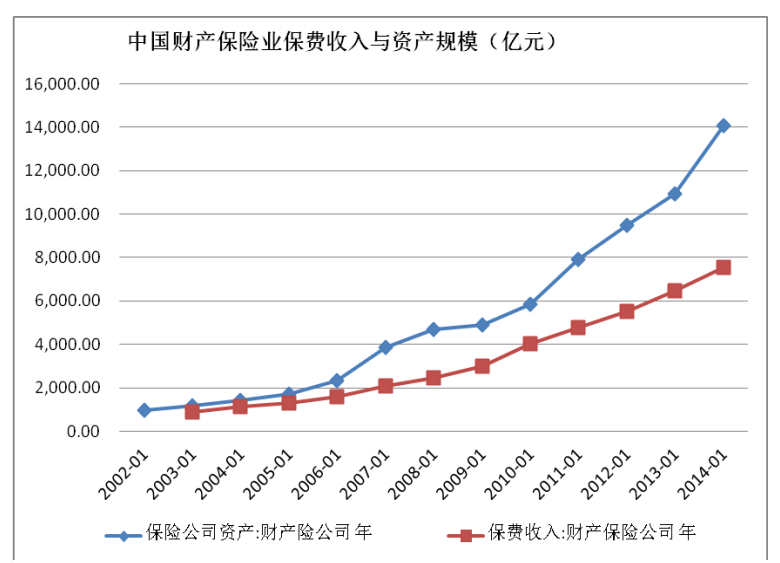

数据来源: Wind 数据整理

图 1 中国财产保险业保费收入与资产规模 
1）财险负债期限短、寿险负债期限特长

保险是负债经营, 由于财险产品和寿险产品在 保险期限上的巨大差异, 导致财险业和寿险业的负 债期限有着天壤之别。我国财产保险公司经营财产 保险业务、短期意外险和短期健康险业务, 承保期 限一般都在一年之内, 导致财险公司的负债期限短。 寿险公司经营人寿保险、健康保险、年金保险和意 外伤害保险, 承保期限多在 5 年以上, 很多产品的 保险期限都是几十年甚至终身, 导致寿险公司负债 期限特别长。

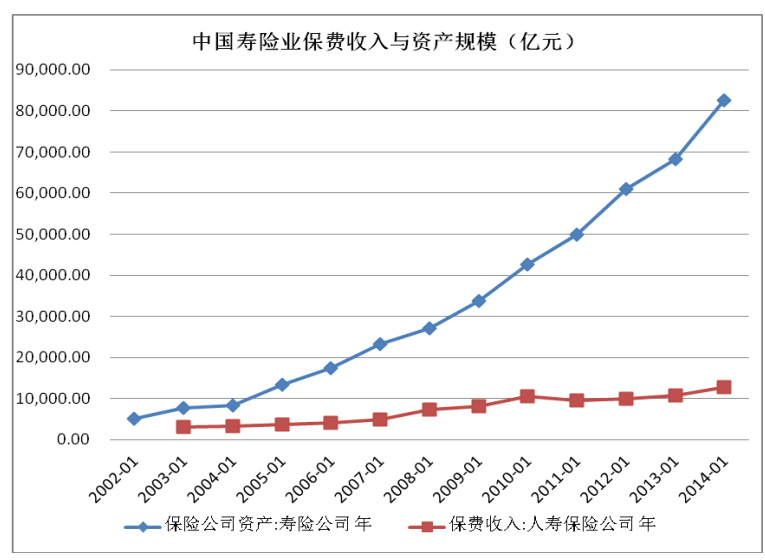

数据来源: Wind 数据整理

图 2 中国寿险险业保费收入与资产规模

正是由于财险业负债期限短, 寿险业负债期限 长，导致寿险业的 “资产规模/保费收入” 远超财险 业, 我国寿险业 2014 年底的资产规模约为当年保费 收入的 7 倍, 而财险业 2014 年底的资产规模约为保 费收入的 2 倍。

2）保险业保费增长速度通常远超 GDP 增速

世界各国的发展经验都表明, 在人均 GDP 达到 一定规模 (大约 2500 美元) 后, 保险业保费增长速 度就会以远超 GDP 增速的速度快速发展, 我国也是 如此, 借势于中国经济的快速发展与居民财富的大 量积累, 过去 30 多年, 我国保费的年平均增长速度 达到 $20 \%$ 以上。

3）我国保险业尚未经历过大的危机

我国保险业一路快速发展, 资产规模与保费收 入不断增长, 但不可忽视的是, 我国保险行业长期 以来都处在保监会等国家监管机构的严格监管下,
尚未遭遇到过特别大的危机, 无论是与国外同行相 比, 还是与我国银行业相比, 我国保险业在风险控 制方面还有许多不足。

\section{2. 日本经济危机与日本保险业危机}

1990 年代, 由于日本经济的大幅波动, 日本保 险业经历了一次大的危机。首先分析日本保险业的 资产负债表的潜在风险，然后分析 1990 年代的日本 经济危机对保险业资产负债表的影响, 观察经济波 动对保险业的冲击。

\section{1 保险业的资产负债表及其潜在风险}

由于资料收集困难，无法收集到 1990 年左右日 本保险业的资产负债表，表 1、2 列出了 2000 年时 日本寿险业和非寿险业的资产负债表（参见附件表 1、表 2)。

可以看到, 从资产端来看, 日本保险业持有大 量金融资产和房地产，而这些资产的价值与宏观经 济状况息息相关，如果遇到经济危机，保险公司持 有的公司债、公司贷款可能面临违约，股市大跌会 迅速降低保险公司持有的股票价值, 房价和土地价 格大跌则会迅速降低保险公司持有的房地产的价 值。从负债端来看, 如果遇到经济危机, 可能会出 现长期的市场利率下行, 而长期利率下行会降低保 险负债的准备金评估利率，从而大幅抬升保险业的 准备金负债规模。当然，从有利的方面来看，市场 利率下行也会提升保险公司的持有的债券的价值。

总体来看, 经济危机可能严重打击保险业, 尤 其是杜杆更大的寿险业的资产负债表, 促使保险业 资产缩水、负债增加, 进而造成净资产下降甚至成 为负值, 偿付能力严重恶化, 甚至出现资金链断裂 导致破产倒闭。

\subsection{0年代的日本经济危机}

1980 年代, 日本出口大幅增长, 经济快速增长, 对美形成巨额顺差，1984 年底日美顺差超过 1000 亿 美元。1985 年 9 月, 美英法德日签订 “广场协议”, 迫使日元升值, 1988 年, 日元兑美元从 238:1 升值 为 $128: 1$ 。

日元升值造成的后果包括：1）出口迅速下降, 带动经济增速下降，日本采取货币宽松政策，大幅 
下调利率，大量资金进入房地产和股市，日本股价、 房价高涨；2）日元升值后，日本企业大举海外投资、 购买美国资产; 3）广场协议同意美元贬值后, 在 日元升值过程中, 大量国际资本进入日本, 购买日 本房地产, 进一步促使房价高涨。结果, 1985 年后 的 5 年间, 日本股市市值增加 3 倍, 房地产价格上 涨 2.4 倍。4）1991 年, 国际资本获利撤离, 泡沫 破裂, 股市、房市大跌, 经济增速大幅下降。之后 的 1997 亚洲金融危机又使日本经济雪上加霜。

如图 3 所示, 日本经济在经历 1980 年代的高速 增长后迅速下滑, 从 1992 年开始, 经济增速一直在 零增长附近徘徊, 走入了失去的 25 年。在日元贬值、 日本经济崩盘后, 日本的股市、住宅价格、土地价 格等无一例外地在同一时间段大幅下跌。图 4 显示 了日元汇率贬值情况, 图 5 显示了日本股市日经指 数变化情况, 图 6 显示了日本城市住宅价格指数变 化情况, 图 7 显示了日本土地价格指数变动情况。

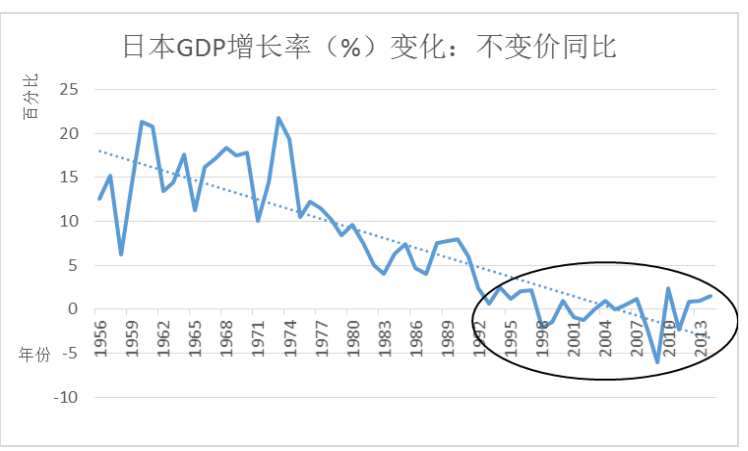

数据来源: Wind 数据整理

图 3 日本 $\mathrm{GDP}$ 增长率 $(\%)$ 变化

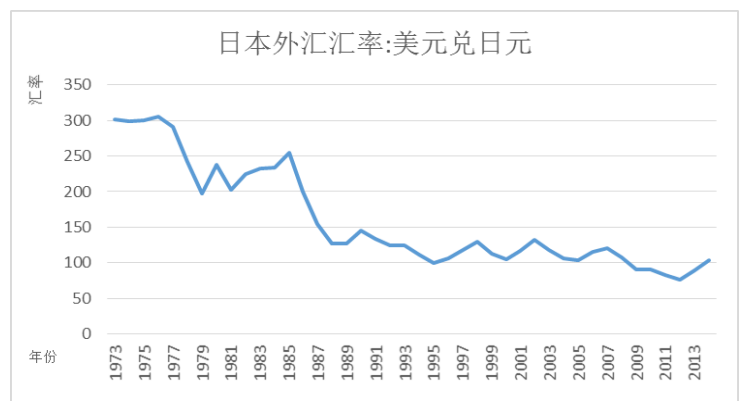

数据来源: Wind 数据整理

图 4 日本外汇汇率:美元兑日元

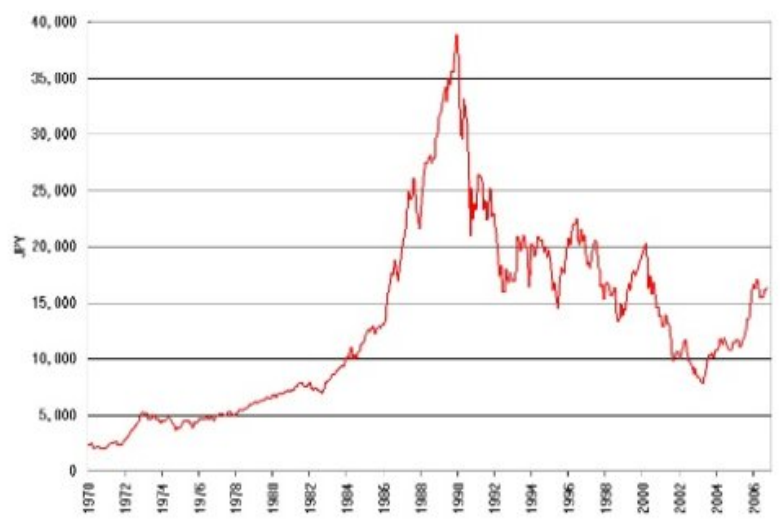

数据来源: 百度网络

图 5 日本股市日经指数

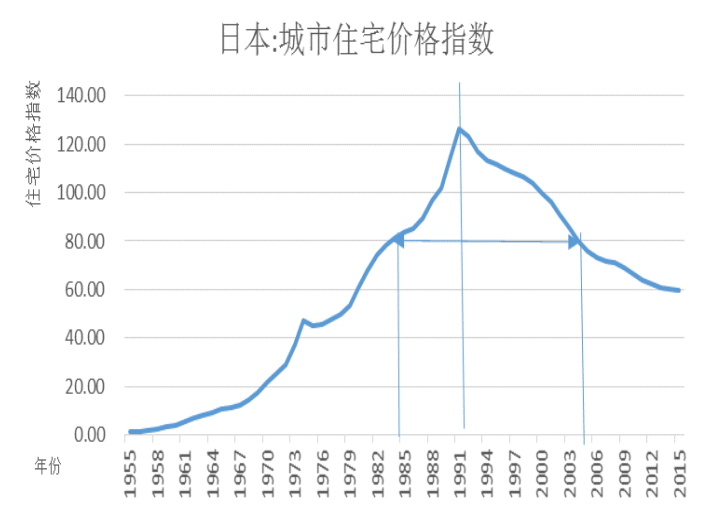

数据来源: Wind 数据整理

图 6 日本城市住宅价格指数

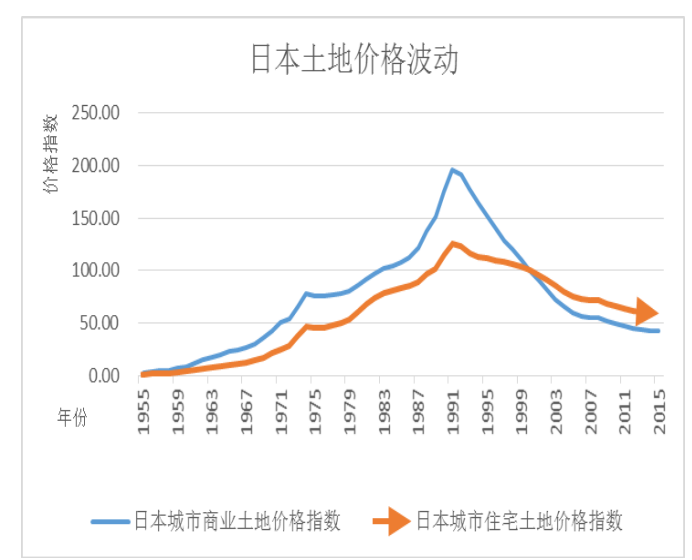

数据来源: Wind 数据整理

图 7 日本土地价格波动 


\section{3 经济危机带来保险业危机}

首先看对日本保险业资产端的影响：1990 年代 日本经济接近零增长, 日本的股市、住宅价格、土 地价格等无一例外地在同一时间大幅下跌, 大量企 业经营状况恶化。结果, 保险公司持有的公司债、 公司贷款出现违约或形成不良资产，保险公司持有 的股票价值大幅缩水, 保险公司持有的房地产的价 值也大幅缩水。但也有有利因素, 即利率下行造成 保险业持有的固定收益类资产价值上升。总体来看, 日本保险业的资产规模有所下降，但规模不太大。

再看对负债端的影响: 经济危机发生后, 日本 采取了货币宽松政策, 试图刺激经济上行, 但经济 还是由于人口老龄化、技术创新瓶颈等原因持续低 迷, 造成了市场利率的长期低位运行。而长期利率 下行会给寿险业带来严重的利差损问题, 或者称为 准备金评估利率降低造成的负债大幅增加问题。由 此, 日本寿险业的负债规模由于利率下行而大幅升 高。

资产略微缩水和负债大幅增加, 使日本寿险业 的净资产大幅缩水，如表 1 所示，到 2000 年时，日 本寿险业的净资产居然只有总资产的 $3.2 \%$ 。而在健 康运行状况下，寿险业的净资产大致在总资产的 $8 \%$ 左右。其中的一些寿险公司已经资不抵债, 面临破 产。

1997 年, 日本二战后倒闭了首家保险公司一一 日产生命保险公司, 随后, 东邦生命保险公司、第 百生命保险、第一火灾海上保险、大正生命保险、 千代田生命保险、协荣生命保险、东京生命保险、 大成火灾等多家保险公司相继破产，引起了日本金 融界的强烈震动。表 3 概述了 2000 年左右日本寿险 业倒闭的 7 家寿险公司的基本情况 (参见附件表 3)。

有些意外的是, 同期还有少量财险公司也破产 了，如第一火灾海上保险和大成火灾保险。意外的 原因是因为财险公司通常自只做短期保险业务, 不 存在承诺客户保证收益率的问题。表 4 是第一火灾 海上保险的发展历史（参见附件表 4)。

\section{4 剖析日本保险业利差损问题}

上述研究发现, 经济危机对保险业的打击有资 产端的影响, 更有负债端的影响, 集中体现为保险
业的巨额利差损问题。

日本的经济在二战后开始高速增长，每年增长 高达 $10 \%$ 以上, 经济起飞和高速增长阶段必然面临资 金短缺，所以市场利率较高，因此这时期内日本保 险业销售的寿险产品大多利率很高, 高利率为保险 公司带来大量保费的同时，也为日后的危机埋下了 隐忧。到了 90 年代, 经济增长乏力, GDP 增速甚至 出现了负增长, 资金不再短缺, 市场利率接近零利 率，寿险业产生了严重的利差损问题。

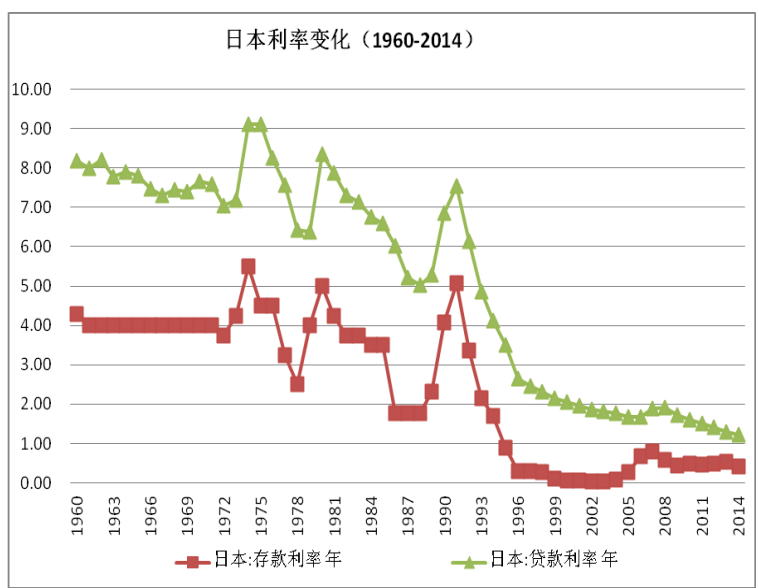

数据来源: Wind 数据整理

图 8 日本存贷款利率变化（1960-2014）

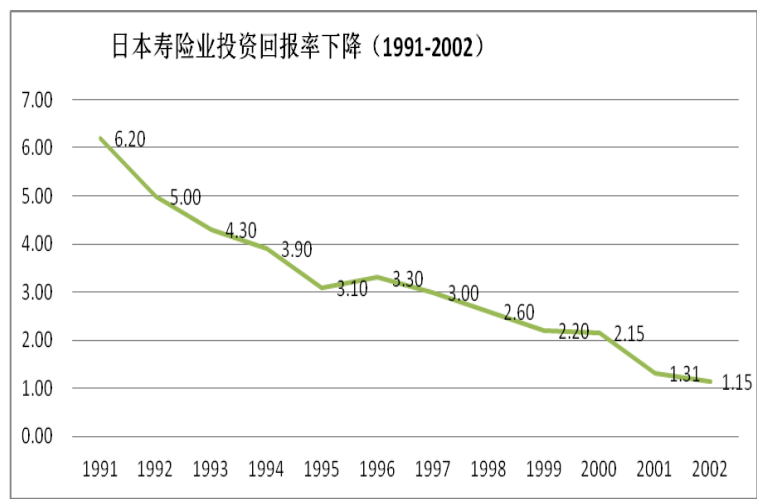

数据来源: 周国端. 保险财务管理: 理论、实务、 案例，中信出版社，2015

图 9 日本寿险业资产投资回报率变化

图 8 为日本利率的历史变化情况，表 5 为不同 年份日本寿险业的预定利率（1952-2002）（参见附 
件表 5), 图 9 为日本寿险业资产投资回报率的变化 情况 (1991-2002)。由于寿险产品是长期产品, 长 期意味着承诺客户的固定回报率是长期固定的, 而 在保险期限内利率逐渐下行造成寿险公司资产投资 回报率下降后, 必然会给寿险业带来利差损问题。 前期保证利率产品销售越多, 后期利率下行程度越 严重, 后期利率下行或低位运行时间越长, 利差损 规模就会越大。

日本寿险业的利差损问题实际在 1980 年代利率 下行后就出现了。为了弥补利差损, 1980 年代, 保 险公司大量投资于回报率高的股市和房地产，在 20 世纪 80 年代末 90 年代初, 由于日本实体经济不振, 在宽松的货币条件下，大量资本流入股市，房地产， 使得价格远远高出了合理价位。广场协定后, 股市 市值以每年 $30 \%$ 速度增加, 土地价格每年上涨 $15 \%$, 而同时期日本的名义 GDP 增长只有 5\%左右, 泡沫越 来越大, 股价不断上涨, 房地产价格也不断走强, 保险公司便寄希望于依靠股市和房地产的投资弥补 利差损, 但 1991 年国际资本流出后, 随之泡沫破裂, 股价一落千丈, 日经指数直到今天也没有再达到过 当初的高位。房地产价格也发生崩盘, 2005 年房价 竟然与 20 年前的房价基本一致。随着股市、房价的 暴跌, 保险业不仅没有达到弥补利差损的目的, 反 而使得资产进一步贬值, 引起更大的危机。

此外，第一火灾海上保险公司是一家相互制保 险公司, 历史悠久, 本不应该出现利差损问题。但 是, 如表 4 所示, 该公司为了实现迅速增长, 从 1963 年开始销售长期的储蓄性火灾保险作为主打产品, 并承诺了高额的利率, 这就为日后的破产埋下了隐 忧。伴随着日本高速的发展, 资产也不断增加, 到 1992 年, 资产达到 1000 亿日元, 但其保费收入中, 两款高回报率承诺的长期储蓄产品占到 $80 \%$, 到 2000 年, 利差损有 120 亿日元之巨, 在金融监管厅下令 停止一部分业务后, 资产持续缩水, 负债不断加大, 到破产时, 已经资不抵债, 负债 12706 亿日元, 股 东权益为 -1246 亿日元。

可见, 无论是寿险公司还是财险公司, 利差损 问题是日本保险业危机的主要原因, 但根源是宏观 经济的大幅波动及保险业的错误预期。

\section{3. 台湾经济低迷与台湾保险业危机}

\section{1 台湾2000年代的经济低迷}

作为亚洲四小龙之一的台湾在战后发展迅猛, 出口导向型的政策与日本极为相似, GDP 增长率在 20 世纪 60 年代平均为 $10 \%, 70$ 年代平均为 9. $4 \%$, 80 年代平均为 $8.1 \%, 90$ 年代平均为 $6.3 \%$ 。台湾 GDP 增长率变动情况见图 10 。

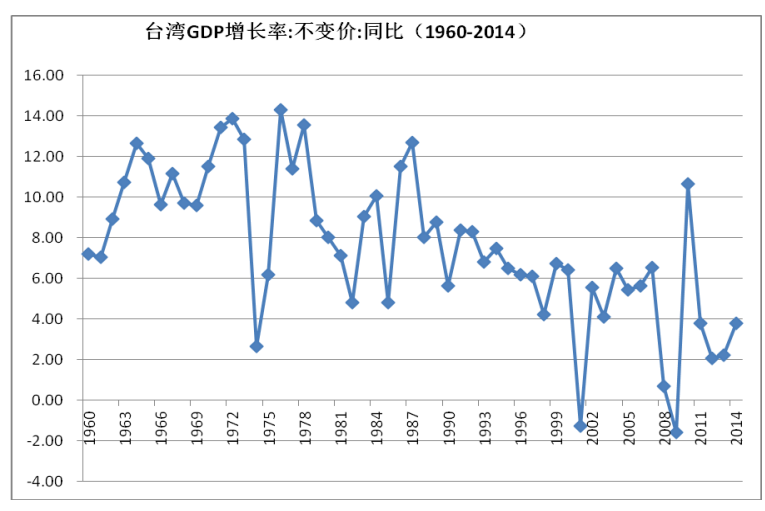

数据来源: Wind 数据整理

图 10 台湾 GDP 增长率变化 (不变价)

21 世纪初, 台湾经济增长率下降, 出现 2 次负 增长。2001 年, 美国互联网泡沫破裂, 全球经济开 始走缓, 以出口电子产品为主的台湾经济受到波及, 出口负增长 $17.1 \%$, 电子产业为龙头的岛内工业衰 退, 产业大量转移到其他地区。经济下行的同时, 利率也开始不断走低, 金融机构普遍遭遇困境, 据 当时穆迪估计，台湾银行实际呆坏帐率应高于 $15 \%$, 总呆坏帐金额可能高达 600 亿美元, 占 GDP 的 $20 \%$ 。 台湾利率变化情况见图 11。

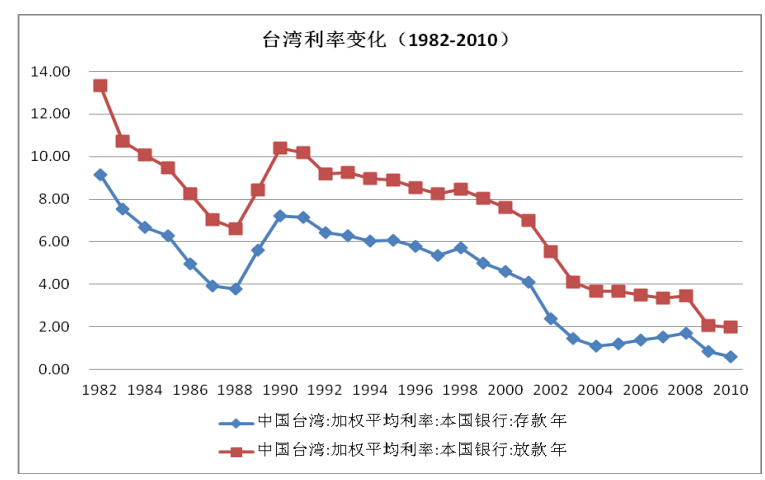

数据来源: Wind 数据整理

图 11 台湾存贷款利率变化 


\section{2 经济低迷对寿险业的影响}

与日本情况类似, 台湾寿险业在经济增速较快、 利率水平较高的时期销售了大量高预定利率保单, 然后, 在经济下滑的 2000 年代, 在市场利率不断走 低的情况下, 台湾保险业开始出现利差损问题。台 湾寿险业新保单平均预定利率与保险资产收益率如 图 12 所示, 可以看到, 与市场利率变化水平基本一 致, 台湾寿险业资产投资收益率从 1990 年代中期开 始逐渐下滑, 由此一定会造成长期固定回报类保单 的利差损问题，1990 年代中期，台湾寿险公司预定 利率保单的承诺利率高达 $7.8 \%$, 而 2004 年寿险业的 投资回报率在 $4 \%$ 左右, 利差损在 $4 \%$ 左右。

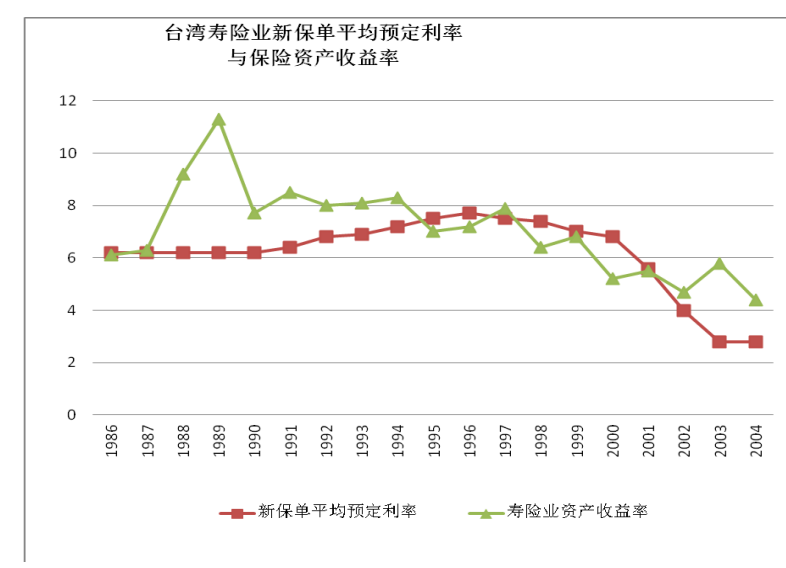

数据来源: Wind 数据整理

图 12 台湾寿险业新保单预定利率与 保险资产收益率

与日本保险业危机时不同, 在台湾此次危机中 有大量的外资保险公司出逃。按照《国际会计准则 第 4 号》的规定，欧洲寿险公司财务报表必须采用 公允价值计量。于是, 在台湾经营的欧洲寿险公司 必须为利差损增提大量准备金，导致财务状况恶化， 必须增资补充资本。但是，在 2008 金融危机的打击 下，其母公司也已深陷困境，无法增资。于是，大 量外资保险公司从台湾撤走了。2009 年 2 月, ING 以 195 亿元新台币将台湾 ING 安泰人寿出售给了富 邦金控； 2009 年 6 月，英国保诚以 1 元新台币将台 湾保诚出售给了中国人寿; 2009 年 8 月, Aegon（荷 兰全球人寿）集团以 31 亿元新台币将其台湾子公司 出售。成交价都远低于实际价值。
台湾当局为了缓解台湾当地保险业的财务困 境，消除利差损问题，允许保险公司开展 6 年期储 蓄业务, 由于寿险公司能够提供高于银行存款利率 的投资收益率，寿险公司通过大力发展 6 年期左右 的储蓄产品, 吸引到了大量的资金, 被称为 “银行 存款大搬家”。

\section{4.中国经济波动与保险业风险: 分析与建议}

我国的保险业虽说已经取得了巨大的成功，但 是发展时间短，尚未经历过大危机的洗礼，使得我 国保险业可能会忽视种种风险。从经济增长速度和 市场利率变化来看, 我国也极可能面临经济走缓, 利率低位运行的境地, 我国保险业应该早做准备, 有效应对可能出现的低增长、低利率时代带来的冲 击。

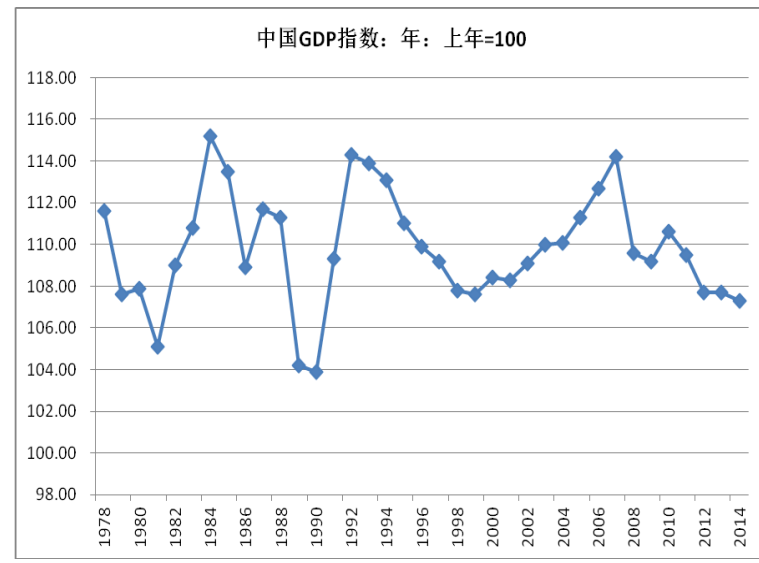

数据来源: Wind 数据整理

图 13 中国 GDP 指数

\section{1 我国保险业1990年代末的利差损问题}

我国保险业从上世纪 80 年代开始复业, 经过 30 多年的发展, 取得了堪称世界瞩目的成绩。但发展 并非一帆风顺, 在上世纪 90 年代, 从 1992 年开始, 中国经济进入快速增长通道, 银行存贷款利率很高, 保险公司据此错误预测了未来利率水平, 销售了大 量长期保证高利率的保险产品, 最高承诺利率高达 复利 $8.8 \%$, 但随后银行存贷款利率不断下降, 保险 公司的投资收益率也随之下降，寿险公司在 2000 年 之后的投资收益率平均水平在 $5 \%$ 左右, 导致了利差 
损问题。图 13 是中国 GDP 增长变化情况, 图 14 是 中国银行存贷款利率的变化情况, 图 15 是中国最大 寿险公司一一中国人寿 2003 年以来的资产投资收益 率变化情况。

从 1999 年开始, 保监会将寿险产品预定利率一 直维持在 2.5\%的水平, 部分意图就是为了消化 1990 年代末高利率保单的利差损。

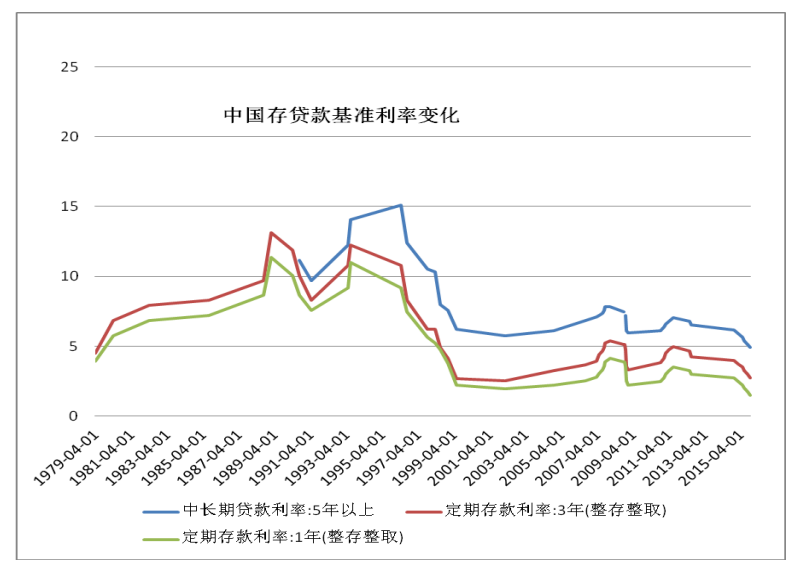

数据来源: Wind 数据整理

图 14 中国银行部门存贷款利率

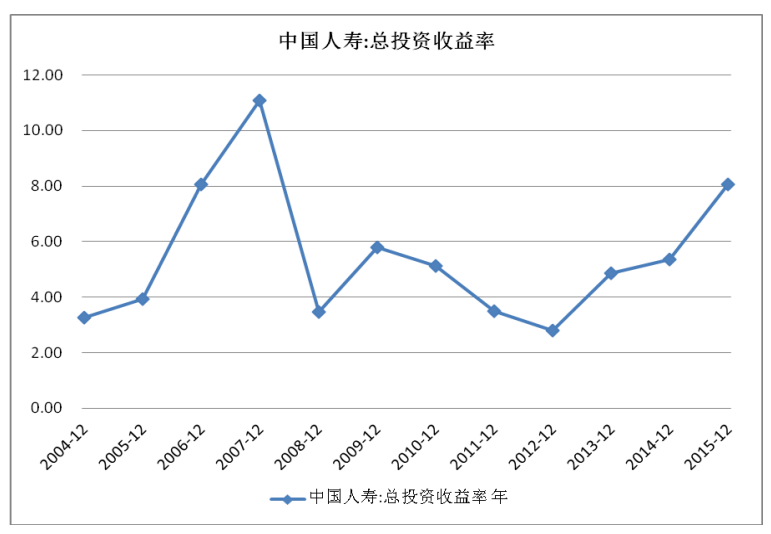

数据来源: Wind 数据整理

图 15 中国人寿的投资收益率变化

\section{2 我国保险业潜在的利差损问题}

近些年来, 全球经济不断减缓, 我国经济增长 减速严重, 市场利率逐渐下行, 低利率时代渐行渐 近。
我国保险业利率设定问题上逐步向市场发展, 将决定权交由市场。2003 年普通寿险预定利率放开, 2015 年万能险、分红险保底利率上限放开, 随着利 率的放开, 势必会引发保险业的利率竞争, 导致寿 险业承诺利率水平上升。例如, 2014 年的开门红产 品, 多数保险公司主打的年金类产品, 采用了保监 会规定的最高利率上限 $4.025 \%$ 。但随着经济由高速 增长转向低速增长, 市场利率水平必然会由高到低 发展, 长期高利率产品几乎必然会产生利差损。

从我国保险公司经营范围来看, 主要风险在寿 险业, 因为寿险业经营长期保险, 负债期限长。但 并非财险公司就没有利差损的风险, 因为许多财险 公司也都推出了 “寿险型” 的保险产品, 而这些产 品将会像寿险公司产品一样遭受利差损的威胁, 所 以，不得不警惕 “寿险型” 财险公司的利差损风险。

\section{3 对中国保险业建议}

针对保险公司可能面临的风险, 结合日本、台 湾保险业发展的相关经验, 我们提出以下建议:

首先, 高利率保险产品要短期化。由于未来利 率很难预测, 保险公司应尽量避免开发销售长期保 证高利率产品。在市场利率水平较高时, 如果希望 通过高保证利率产品占领市场, 应该根据对宏观经 济、金融市场的预测来推出短期化的高收益产品, 因为高利率往往是不可持续的。

其次, 对于长期保险产品, 一定要采取低预定 利率。如前所述, 长期高保证利率产品几几乎必然 会面临利差损问题, 所以, 如果要开发销售长期保 险产品, 一定要将其设计成保证利率较低的、浮动 利率的分红型或万能型产品。

最后, 虽然寿险业风险远大于财险业, 但也要 警惕 “寿险型”财险公司的利差损风险。

\section{参考文献}

[1].胡文富, 日本人寿保险市场概况.保险研究, 2001,(1):47. [2]孙立娟, 梁斯, 朱向辉, 非理性繁荣:日本保险业危机回 顾及对我国的启示.南方金融, 2014,(9):75-79.

[3]水口啓子.変わる生保 消える生保 : よくわかる「生 保」大選別時代の新基準, 東洋経済新報社, 2002 .

[4]池晶, 论日本保险业的危机、对策及启示. 东北亚论坛, 2001,(4):69-72. 
[5]冯玉梅, 日本保险业危机与中日保险业对比. 现代日本经 济, 2001,(3):16-21.

[6]于超银, 日本保险公司破产对我国保险业风险防范的启 示. 现代日本经济，2001,(3):26-31.

[7]胡坤, 日本保险业的危机与启示. 金融研究, 2000,(11):100-108.

[8]吉玉荣, 张爱红, 张维, 日本保险业危机对我国保险监 管的启示. 南京审计学院学报, 2007,(2):36-39.

[9]周国端, 保险财务管理: 理论、实务、案例. 中信出版 社, 2015
[10] 孟昭亿, 保险资金运用国际比较. 中国金融出版社, 2005

\section{（本文受国家自然科学基金面上项目 “小概率大损 失风险投保不足的实验研究”（批准号：71173144） 的资助。)}

\section{附件:}

表 1 日本寿险业资产负债表（2000 年）

\begin{tabular}{ll|lr}
\hline 资产: & & \multicolumn{1}{|c}{ 负债: } \\
\hline 国内有价证券: & $57.6 \%$ & 准备金: & $90 \%$ \\
政府债券 & $16.6 \%$ & 价格波动储备: & $0.4 \%$ \\
公司债券 & $9.3 \%$ & 其他负债: & $9.6 \%$ \\
股票 & $15.4 \%$ & & \\
贷款: & $26.1 \%$ & & \\
政府贷款: & $2.5 \%$ & & \\
公司贷款: & $17.2 \%$ & & \\
现金+命令贷款: & $5.3 \%$ & 股东权益: \\
房地产: & $4.3 \%$ & 总资产的 \\
国外贷款: & $2.1 \%$ & & \\
\hline
\end{tabular}

数据来源: 孟昭亿, 《保险资金运用国际比较》, 中国金融出版社, 2005

表 2 日本非寿险业资产负债表（2000 年）

\begin{tabular}{ll|ll}
\hline 资产: & & 负债: & \\
\hline 存款: & $6 \%$ & 准备金: & $83.7 \%$ \\
命令贷款: & $1.7 \%$ & 其他负债: & $16.3 \%$ \\
证券: & $62.3 \%$ & & \\
日本中央政府债券 & $5.4 \%$ & & \\
地方政府债券 & $4.0 \%$ & & \\
公司债券 & $13.4 \%$ & & \\
股票 & $26.8 \%$ & & \\
国外证券 & $11.4 \%$ & & \\
其他证券 & $1.3 \%$ & 股东权益: \\
贷款: & $11.6 \%$ & 总资产的 \\
房地产: & $4.7 \%$ & \\
其他资产: & $13.7 \%$ & \\
\hline
\end{tabular}

数据来源：孟昭亿，《保险资金运用国际比较》，中国金融出版社，2005 
表 3 日本寿险公司破产概况

\begin{tabular}{|c|c|c|c|c|c|c|c|}
\hline 破产公司 & $\begin{array}{c}\text { 日产生 } \\
\text { 命 } \\
\end{array}$ & 东邦生命 & 第百生命 & 大正生命 & $\begin{array}{c}\text { 千代田生 } \\
\text { 命 }\end{array}$ & 协荣生命 & 东京生命 \\
\hline 成立时间 & 1909 & 1898 & 1915 & 1914 & 1904 & 1935 & 1895 \\
\hline 破产时间 & 1997.4 & 1999.6 & 2000.5 & 2000.8 & 2000.10 & 2000.10 & 2001.3 \\
\hline 破产前资产总额 & 20.609 & 28.046 & 21.885 & 2.044 & 35.019 & 46.099 & 10.150 \\
\hline 破产后资不抵债额 & 3.000 & 6.500 & 3.200 & 365 & 5950 & 6895 & 325 \\
\hline 破产前预定利率 & $\begin{array}{c}3.75-5.5 \\
0\end{array}$ & 4.79 & 4.46 & 4.05 & 3.70 & 4.00 & 4.20 \\
\hline 破产后预定利率 & 2.70 & 1.00 & 1.00 & 1.00 & 1.50 & 1.75 & 2.6 \\
\hline
\end{tabular}

数据来源：水口啓子.变わる生保 消える生保 :よくわかる「生保」大選別時代の新基準 $[\mathrm{M}]$.東洋経済新報 社, 2002

表 4 第一火灾海上保险公司发展历史及破产情况

\begin{tabular}{ll}
\hline 1949 年 & 第一火灾海上保险公司成立，属于相互制公司 \\
& 销售储蓄型火灾保险，保险期限多为 10 年，承诺高预定利率，为日本财产保险业界第一 \\
& 款这样的产品; \\
& 该产品一直作为主打产品，引入营销员制度 \\
1969 年 & 销售储蓄型分红意外伤害保险，保险期限 10 年甚至以上。 \\
1972 年 & 总资产达 500 亿日元 \\
1987 年 & 总资产达 5000 亿日元 \\
1992 年 & 总资产达 10000 亿日元，两款储蓄型产品保费占比近 $80 \%$ \\
1999 年 & 与协荣生命进行资本和业务合作：基金（相当于资本金）由 35 亿日元增至 416 亿日元。 \\
1999 年 3 月 & 风险保费收入 597 亿日元，排名 17 位; 但其总资产却排名第 8 位。 \\
2000 年 & 利差损达 120 亿日元，金融监管厅下令停止一部分业务 \\
2000 年 3 月 & 宣布破产。破产时公司：资产 11461 亿日元，负债 12706 亿日元，股东权益-1246 亿日元 \\
2001 年 & 所有保险合同转移给财产保险契约者保护机构 \\
\hline
\end{tabular}

数据来源：孟昭亿，《保险资金运用国际比较》, 中国金融出版社, 2005

表 5 不同年份日本寿险业的预定利率（1952-2002）

\begin{tabular}{|c|c|c|c|c|c|c|c|c|c|c|c|}
\hline 保险期限 & 1952 & 1976 & 1981 & 1984 & 1990 & 1993 & 1994 & 1996 & 1999 & 2001 & 2002 \\
\hline$<10$ 年 & \multirow[t]{3}{*}{4.0} & 5.5 & 6.0 & 6.3 & 5.8 & \multirow[t]{3}{*}{4.8} & \multirow[t]{3}{*}{3.8} & \multirow[t]{3}{*}{2.8} & \multirow[t]{3}{*}{2.0} & \multirow[t]{3}{*}{1.5} & \multirow[t]{3}{*}{$1.5-0.75$} \\
\hline $10-20$ 年 & & \multirow[t]{2}{*}{5.0} & 5.5 & 6.0 & \multirow[t]{2}{*}{5.5} & & & & & & \\
\hline$>20$ 年 & & & 5.0 & 5.5 & & & & & & & \\
\hline
\end{tabular}

数据来源: 2003 年 2 月《周刊朝日》, 申万研究 